\title{
The protein import apparatus of chloroplasts
}

\author{
Jürgen Soll and Heike Alefsen
}

Soll. J. and Alefsen. H. 1993. The protein import apparatus of chloropiasts. - Physiol Plant. 87: 433-440.

\begin{abstract}
Routing of cytosolically synthesized precursor proteins into chloroplasts is a specitic process which involves a multitude of soluble and membrane components. In this review we will focus on early events of the transtocation pathway of nuclear coded plastidic precursor proteins and compare import routes for polypeptides of the outer chloroplast envelope to that of internal chloroplast compartments. A number of proteins housed in the chloroplast envelopes have been implied to be involved in the translocation process. but so far a certain function has not been atsigned fo atn of these proteins. The only exception could be an envelope localized has 70 homoligue which could retain the import competence of a precursor protein in transit into the organelle.
\end{abstract}

Key words - Chloroplasts. envelope membrancs, import appatatus. protein transport

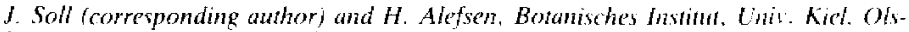
hausenstrabe 40. D-2300 Kiel l. Geman.

\section{Introduction}

The biogenesis of plastids requires the coordinated synthesis, transport and assembly of polypeptides originating in the cytosol and those made by the organelles themselves. Description and characterization of the translocation and sorting pathways of nuclear coded precursor proteins destined for the chloroplast have been attractive targets for research in recent years (for reviews see: Chua and Schmidt 1979. Schmidt and Mishkind 1986. Lubben et al. 1988. Mishkind and Scioli 1988, Keegstra et al. 1989. Smeekens et al. 1990, de Boer and Weisbeek 1992). The general characteristics of this process are: (1) Polypeptides are synthesized in the cytosol with an $\mathrm{N}$-terminal transit peptide which is responsible for routing to the proper organelle (Dobberstein et al. 1977). (2) The N-terminal chloroplast directing targeting sequences have some features in common, e.g., high content of serine and threonine, an uncharged $\mathrm{N}$-terminal region within an overall positively charged transit sequence and primary and secondary motifs next to the cleavage site (Karlin-Neumann and Tobin 1986, Smeekens et al. 1986, von Heijne et al. 1989, Bartling et al. 1990, von Heijne and Nishikawa 1991). In case the precursor protein is directed to the thylakoid lumen the transit peptide contains in its Cterminal part a thylakoid transfer domain (Smeekens et al. 1986). with properties similar to signal sequences (Smeekens and Weisbeek 1988. Bassham et al. 1991). The general framework is however less pronounced than for mitochondrial targeting sequences (Hartl et al. 1989). (3) Import is initiated by binding of the chloroplast targeting domain 10 proteinaceous receptors localized on the surface of the organelle followed by translocation through the outer and inner envelope membranes (Cline et al. 1985). In some instances, regions in the mature protein have been suggested to be important for efficient translocation in addition to a functional transit sequence (Kuntz et al. 1986. Wassmann et al. 1986). (4) ATP hydrolysis is required at two stages during this process (see below), while a membrane potential, which is necessary for protein translocation across the mitochondrial membranes, is not required (Grossmann et al. 1980, Flügge and Hinz 1986. Pain and Blobel 1987. Schindler et al. 1987. Hartl et al. 1989). A proton motive force. in many cases in combination with ATP hydrolysis, however, is required for the insertion and translocation of proteins into and across the thylakoid membranes (Cline et al. 1989. 1992. Mould and Robinson 1991, Klösgen et al. 1992).

Received 2 November. 1992 
(5) Inside the organelle the precursor protein is subjected to a maturation event by a stromal processing peptidase (Smith and Ellis 1979) followed by folding and assembly in its proper subcompartment (for details see Bartling et al. 1990, Smeekens et al. 1990. de Boer and Weisbeek 1992 and references therein). Final folding is most likely retarded until the polypeptide reaches its final destination. In case of composed, bipartite transit sequences, e.g.. plastocyanin, a second proteolytic maturation event by a thylakoid processing peptidase leads to the final mature polypeptide (Smeekens et al. 1986, Kirwin et al. 1987).

Due to the excellent and general reviews on protein translocation into chloroplasts (for references see above) and the scope of this review, we will focus here on topics which have emerged very recently or have been neglected earlier, t.e., what is known about the envelope localized import machinery, the mechanism of translocation and the conformation of the precursor protein prior to and during passage through the envelope. We shall compare the translocation route of proteins localized in the stroma or thylakoids to those destined for the outer and inner envelope of plastids. The involvement of molecular chaperones such as hsc 70 homologues or SecA, cpn60, cpn 10 in chloroplasts and other import systems has also been demonstrated and is reviewed in Lubben et al. (1989). Ellis (1990). Neupert et al. (1990). Landry and Gierasch (1991).

Abbreviations - $\mathrm{pFd}$, precursor form of ferredoxin: pLHCP. precursor of the chlorophyll $a / b$ binding protein: $\mathrm{pPC}$. precursor form of plastocyanine: pSSU. precursor form of the small subunit of Rubisco.

\section{Protein structure compatible with translocation}

Protein import into chloroplasts or mitochondria is a posttranslational event. The completed polypeptide chains are released from the ribosomes prior to the translocation process. It is therefore likely that the polypeptides fold into a certain tertiary and globular structure before translocation is initiated. Yet it is unlikely that a large globular macromolecule is able to penetrate a membrane in a specific and ordered fashion. In vivo cytosolic factors should be present to retard the folding process and keep the precursor protein in a conformation compatible with translocation. Experimental evidence that tightly folded proteins are imported into chloroplasts only at very low rates even in their precursor form came from della Cioppa and Kishore (1988). The precursor of 5-enolpyruvylshikimate-3phosphate synthase, synthesized by in vitro-transcription-translation, was allowed to form a tightly folded ternary complex in the presence of shikimate-3-phosphate and the herbicide glyphosate. This regime resulted in a strong decrease of translocated protein. The presence of both of these substrates in an import reaction containing different precursor proteins e.g. pSSU (precursor form of the small subunit of ribulose-1.5bisphosphate carboxylase-oxygenase, Rubisco) was without influence on the translocation efficiency. These data indicate that a tightly folded polypeptide which is "arrested" in its conformation can not be converted by the translocation machinery into a form which is productively imported. Similar results had been obtained earlier for mitochondrial protein translocation (Eilers and Schatz 1986; for a review see Hartl et al. 1989). Further evidence that an unfolded or loosely folded polypeptide conformation favours protein translocation into chloroplasts comes from studies using purified precursor proteins, which are overexpressed in Escherichis colt cells. The purified precursor form of ferredoxin (pFd) is efficiently imported into chloroplasts. if it is denatured (unfolded) in $6 M$ urea prior to the translocation assay (Pilon et al. 1990). The purified precursor of the chlorophyll $a / b$ binding protein ( $\mathrm{pLHCP}$ ) on the other hand seems to require cytosolic factors present in pea leaf extract (Waegemann et al. 1990) or in reticulocyte lysate (Abad et al. 1991) for efficient translocation after denaturation and unfolding in $8 \mathrm{M}$ urea. In addition, urea denatured precursor molecules incubated in the presence of soluble proteins showed a prolonged and drastically increased protease sensitivity in comparison to precursor molecules which were only denatured by urea (Waegemann et al. 1990). This is probably due to a retardation in the folding process mediated hy proteinaceous cytosolic constituents. Purified hsc 70 was also able to support the translocation of urea denatured pLHCP. indicating the involvement of molecular chaperones of the hse 70 family in this process (Waegemann et al. 1990). It remains to be established how the different in vitro results reflect the in vivo situation.

\section{Binding of precursor proteins to receptors on the organellar surface}

Protease treatment of intact organelles or right-side-out envelope vesicles abolishes binding of precursor polypeptides (Cline et al. 1985. Waegemann et al. 1992). Most likely, proteinaceous receptors are responsible for precursor recognition. Each chloroplast possesses about 1500-3500 binding sites for pSSU (Friedman and Keegstra 1989). The binding constant for pSSU to its import receptor was determined to be around $10 \mathrm{n} M$. Protease treatment destroys these specific binding sites, but not low affinity binding components, which could be mediated by other constituents of the import machinery (Friedman and Keegstra 1989). Transfer of the SSU precursor from a protease sensitive site on the chloroplast surface, e.g., receptor bound to the translocation machinery is inhibited by treatment of the intact organelle with phospholipase C (Kerber and Soll 1992). The competence of the receptor to interact with the import machinery could be altered by the hydrolysis of phosphatidylcholine (Fig. 1).

In attempts to characterize the binding process and to 


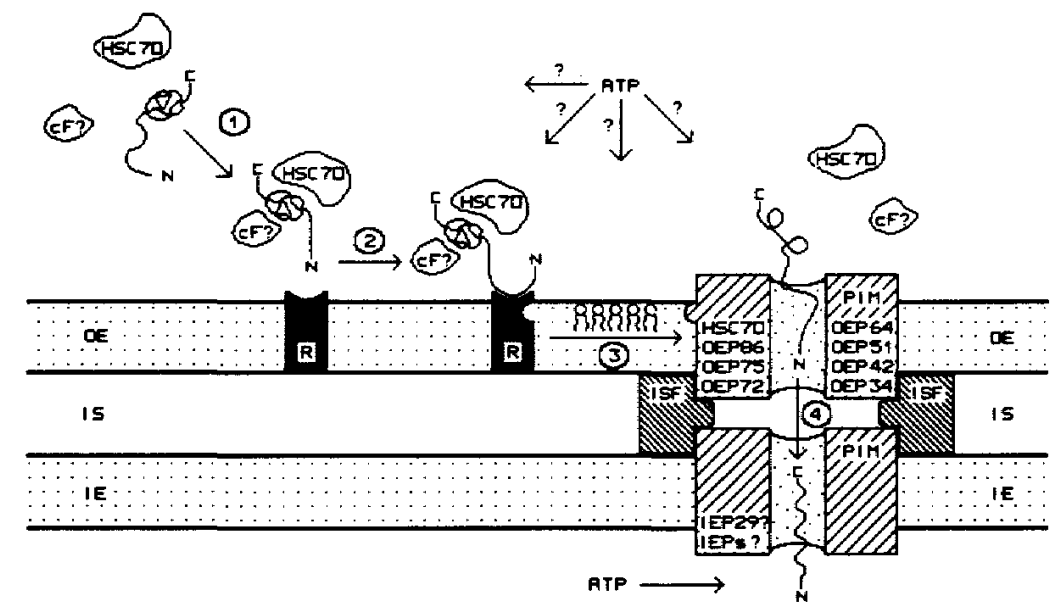

Fig. I. Hypothetical overview of events leading to the posttranslational import of proteins into chloroplasts. Numbers indiente arbitrary steps in this process e.g. (1) retention of import competent conformation by he 70 homologues and putative cytosolic factors $(\mathrm{cF}):(2)$ binding to an outer envelope (OE) localized receptor protein $(\mathrm{R}) ;(3)$ transfer of the precursor from the receptor site into the protein import machinery (PIM): (4) translocation through the envelope membranes by PIM formed of outer envelope proteins (OEP) and inner envelope proteins (IEP). Intermembrane space factors (ISF) might be required for a productive translocation cycle.

determine whether different receptor populations are involved in the import pathway, chemically synthesized peptides were used. In general, peptides of 20-30 amino acid length, which were homologous to parts of the chloroplast transit sequence, were applied and shown to influence the import reaction at different stages (Buvinger et al. 1989. Perry et al. 1991, Schnell et al. 1991). Peptides corresponding to the $\mathrm{N}$ - or C-terminal portion of the transit sequences of pSSU. pLHCP. pFd and pPC (precursor form of plastocyanine) seemed to inhibit the import pathway at a step after the receptor binding cvent (Buvinger et al. 1989. Perry et al. 1991). However. peptides that contained amino acid sequences corresponding to the central part of the transit peptide seemed to influence directly the binding event of the precursor protein to the receptor polypeptide (Perry et al. 1991. Schnell et al. 1991). So far these experiments indicate a common receptor for most of the bulk protein import or at least for the precursor proteins listed above, which represent major chloroplast constituents of different localization. Though the influence of the synthetic peptides on the import pathway seems to be specific, it is not known whether these individual domains, as represented by the single peptides, can fold into a critical, productive conformation. as the entire transit peptide normally does, to interact with single components of the envelope import apparatus. This might be one reason for the rather high peptide concentrations $(2-40 \mu M)$ needed for $50 \%$ import inhibition of authentic precursor polypeptides. The use of purified, authentic precursor proteins seems to overcome these problems. A 10 to 100 fold more efficient competition between the precursor forms of PC, SSU and Fd was demonstrated by de Boer (A. D. de Boer 1991. Thesis. Univ. of Utrecht, The Netherlands).

\section{Energy requirement of the import event}

ATP hydrolysis is required at least at two distinct steps during the import pathway (Fig. 1). while a membrane potential plays no role (Grossmann et al. 1980). Higher concentrations of ATP are required for complete translocation into the stroma $(>200 \mu M)$ (Flügge and Hinz 1986, Pain and Blobel 1987. Schindler et al. 1987. Theg et al. 1989). ATP necessary for translocation seems to be hydrolyzed in the stroma or at the inner leaflet of the inner envelope membrane. Lower ATP concentrations (1-100 $\Lambda M$ ) are needed for binding of the precursor 10 the receptor in isolated organelles and right-side-out envelope vesicles (Olsen et al. 1989. Waegemann and Soll 1991, Olsen and Keegstra 1992). The components which hydrolyze the ATP during the binding phase of the precursor to the outer envelope membrane surface have not yet been identified. It also remains to be established, whether they are envelope or cytosolic polypeptide constituents. Only a few explanations are suggested here for the possible function of this ATP hydrolysing step: (1) the ATP dependent phosphorylation of a $51 \mathrm{kDa}$ outer envelope protein. which could be a component of the transport apparatus. is increased about 3-fold upon precursor binding (Hinz and Flügge 1988, see also below); (2) hydrolysis of ATP by molecular chaperones, in this case cytosolic hsc 70, favours the dissociation or release of the precursor from hsc 70 (Pelham 1986) and could be required at the cytosolorganelle interface to allow productive interaction with 
the receptor: (3) hydrolysis of ATP by components of the intermembrane space or the inner leaflet of the outer membrane might be necessary for a functional protein import apparatus via protein phosphorylation (Fig. 1) (Olsen and Keegstra 1992). Chloroplast-pSSU interaction under low ATP $(10 \mu M)$ concentration. which does not support import, is not halted at the receptor stage, but the precursor is able to move into the import apparatus where it is partially protected against protease (Waegemann and Soll 1991).

\section{Identification of single members of the chloroplast protein translocation machinery}

A number of different approaches, e.g. chemical crosslinking, phosphorylation, antiidiotypic antibodies and isolation of membrane complexes have been applied to identify polypeptides involved in the translocation process. (1) Cornwell and Keegstra (1987) identified a major crosslink product of $66 \mathrm{kDa}$ after incubation of intact chloroplasts with pSSU, minor crosslink products were of 25.57 and $80 \mathrm{kDa}$. Using a similar approach Kaderbhai et al. (1988) obtained a crosslink product of $52 \mathrm{kDa}$ identified as the large subunit of Rubisco and a crosslink product localized in the inner envelope membrane protein of $30 \mathrm{kDa}$. (The molecular mass data mentioned above are estimates after subtraction of the molecular mass of the cross linked precursor). (2) Upon precursor binding to spinach chloroplasts a specific increase in the ATP dependent phosphorylation status of a protease sensitive outer envelope protein of $51 \mathrm{kDa}$ was observed. suggesting its involvement in the import process (Hinz and Flügge 1988). (3) An antibody was raised against a transit peptide specific antibody, which was shown to inhibit import (Pain et al. 1988). The antiidiotypic antibodies, which are supposed to mimic the binding properties of the transit peptide. in this case those of pSSU, recognized protease-sensitive polypeptides on the surface of intact chloroplasts as demonstrated by immunfluorescence microscopy and as would be expected for a receptor protein. In immunoblot analysis the antiidiotypic antibodies labelled primarily the large subunit of Rubisco and a $30 \mathrm{kDa}$ protein which was subsequently shown to be the major polypeptide constituent of envelope membranes (see also Joyard et al. 1991). The full length cDNA clone of the $30 \mathrm{kDa}$ receptor protein was found to be identical to the $30 \mathrm{kDa}$ phosphate-translocator protein from pea (Flügge and Heldt 1981. Flügge et al. 1989. Schnell et al. 1990, Willey et al. 1991). The conflicting studies provoke a number of questions: (1) The chloroplast outer envelope contains about 3000 protease-sensitive precursor binding sites which represent maximally $0.3 \%$ of the total envelope protein (Friedman and Keegstra 1989. Joyard et al. 1991), while the major envelope protein at $30 \mathrm{kDa}$, represents $10-15 \%$ of the total envelope protein (Joyard et al. 1983, Cline et al. 1984). (2) Import studies demonstrate that translocation of the in vitro translation product of the cDNA clone for the $30 \mathrm{kDa}$ protein from pea and spinach occurs into a proteaseinsensitive localization in the envelope membranes (Flügge et al. 1989. Willey et al 1991). (3) The phosphate translocator activity and the protein import efficiency is largely diminished by incubating the chloroplasts with $4,4^{\prime}$-diisothiocyanostilbene-2.2'-disulphonic acid. While the phosphate transport activity can be protected from this inhibition by a pretreatment of the chloroplasts with pyridoxalphosphate. this regime is ineffective in shielding the protein import activity (Flüge et al. 1991), suggesting that these two activities reside in two different polypeptides. (4) Outer envelope membranes from pea chloroplasts are isolated as right-sideout membrane vesicles (Waegemann et al. 1992) and bind pSSU in an ATP. receptor and transit peptide dependent manner (Waegemann and Soll 1991. Soll and Waegemann 1992). This membrane population can be used as a bona fide system to study early events in the import pathways. e.g. binding of precursor proteins. Outer envelope membranes which exhibit this specific interaction with pSSU do not contain immunreactive material to antibodies against the $30 \mathrm{kDa}$ protein (phosphate translocator). while binding of precursor proteins to the inner membrane which contains all of the $30 \mathrm{kDa}$ protein is only $20 \%$ compared to outer membranes (Flügge et a1. 1991). Interestingly. Mom 38, a part of the integral mitochondrial import apparatus. shares some homology with the mitochondrial phosphatetranslocator (Kiebler et al. 1990).

Outer envelope vesicles not only bind specifically pSSU but the precursor is partially inserted into the membrane-embedded translocation machinery as can be deduced from identical translocation intermediates observed in the organellar and the isolated membrane import system (Waegemann and Soll 1991). A pSSUcontaining membrane complex was isolated after solubilization of pSSU-loaded outer envelope membrane vesicles by sucrose density centrifugation. This fraction consists of about 10 outer envelope polypeptides. identified either by molecular mass or immunological methods $(86,75,72,64,54,52,42,34 \mathrm{kDa}$ and minor components) (Waegemann and Soll 1991. Soll and Waegemann 1992).

In a variation of the procedure, Soll and Waegemann (1992) were able to isolate large parts of the translocation apparatus as a functional active unit. The interaction of this import complex with the precursor protein depended strictly on the conditions outlined in Tab. 1. Protease-protected translocation intermediates were identical to those detected in chloroplasts. A possible explanation for this finding is that the precursor protein is not only interacting with the surface of the complex but passes through a pore formed by the import apparatus where it is partially protected by protease (Fig. 1).

Outer envelope membranes and the isolated import complex do contain an hsc 70 homologue (Marshall et al. 1990, Waegemann and Soll 1991), which could play a 
Tah. 1. General characteristics of protein translocation into chloroplasts from higher plants.

\begin{tabular}{lcc}
\hline $\begin{array}{l}\text { Import } \\
\text { characteristics }\end{array}$ & \multicolumn{2}{c}{ Chloroplast compartment } \\
\cline { 2 - 3 } & $\begin{array}{c}\text { Inner envelope. } \\
\text { stroma, thylakoids }\end{array}$ & Outer envelope \\
\hline Precursor & $\begin{array}{l}\text { p30kDa } \\
\text { pSSU } \\
\text { pLHCP }\end{array}$ & OEP 7 \\
OEP 14 & No \\
$\begin{array}{l}\text { ATP dependent } \\
\text { Receptor dependent } \\
\text { (proteasc sensitive) }\end{array}$ & Yes & No \\
Cleavable N-terminal & Yes & No \\
transit peptide & &
\end{tabular}

role in the translocation mechanism. Von Heijne and Nishikawa (1991) propose that chloroplast transit peptides form a perfect random coil, which would require guidance by molecular chaperones during their passage through the import apparatus. Antibodies against hsc 70 are able to coimmunoprecipitate the pSSU precursor protein after solubilisation of the import complex, demonstrating the close interaction between chaperone and precursor at this stage (Waegemann and Soll 1991). Even though the definite polypeptide composition of the import complex as well as the involvement and function of its polypeptide constituents in the translocation event still have to he established. isolation of a functional import complex might result in a better understanding of the translocation mechanism.

\section{Protein translocation into the inner chloroplast envelope}

So far only two inner envelope proteins have been cloned and their import behaviour has been analysed. Import features which they share with proteins destined for the internal plastidal compartments are (1) ATPdependent import: (2) protease-sensitive components on the organellar surface are necessary for recognition; (3) a cleavable transit peptide (Flügge et al. 1989 , Dreses-Werringloer et al 1991). However, the transitpeptides are unusual in the respect that they exhibit the potential to form an amphiphilic $\alpha$-helix (Willey et al. 1991), a feature thought to be characteristic for mitochondrial targeting signals. The phosphate translocator contains a charged $\mathrm{N}$-terminal sequence in its transit peptide and is rich in Arg and has a lower percentage of Ser and Thr. The C-terminal part of the transit sequence seems not to contain a $\beta$-strand domain (Willey et al. 1991), typical for chloroplast proteins of the stroma and thylakoids (von Heijne et al. 1989). The $\beta$-strand domain, present in e.g. pSSU, was suggested to serve as an envelope transfer domain that directs proteins into the stroma (Dreses-Werringloer et al. 1991). Even from these few examples it becomes evident that certain details of the precursor polypeptide structure and maybe also of the import pathway could be significantly distinct between stromal or thylakoid proteins and envelope proteins, respectively; however. more examples have to be studied to obtain conclusive evidence.

\section{Protein translocation into the outer chloroplast envelope}

Translocation (insertion) of outer envelope proteins studied until now is very distinct from import of those destined for inner plastid compartments. Two proteins from either spinach (Salomon at al. 1990 ) or pea ( $L i$ et al. 1991) have been cloned and their translocation studied. The two polypeptides do not contain a cleavable targeting peptide, nor do they require protease sensitive components on the organellar surface for translocation: furthermore. integration in to the outer membtane is independent of ATP (Tab. 1). So far, the translocation mechanism and envelope components responsible for recognition and insertion of these outer membrane proteins have not been further analysed.

\section{Development of the import apparatus}

Different types of plastids have been demonstrated to he competent for precursor protein uptake, even if these proteins are not present at the special differentiation stage. e.g. etioplasts (Schindler and Soll 1986). leucoplasts (Halpin et al. 1989). amyloplasts (Strzalka et al. 1987), proplastids (Dahlin and Cline 1991). In general pSSU and pLHCP import was studied. Interestingly Dablin and Cline (1991). found that import capability declines as etioplasts and chloroplasts reach their fully mature form. How this down regulation is accomplished remains unclear. Mature etioplasts could be reactivated to high import efficiency by the exposure to light. A $400 \%$ increase of precursor protein uptake was found after 5-7 h of continuous light. The increase might be due to a de novo synthests of constituents of the import apparatus (Dahlin and Cline 1991): however, different regulatory or developmental processes are also likely to be involved.

\section{Sorting of precursor proteins between chloroplasts and plant mitochondria}

Conflicting reports have been published concerning the specificity of precursor protein sorting between plant mitochondria and chloroplasts. Hurt et al. (1986) used a fusion protein consisting of the transit peptide of the small subunit of Rubisco from the green alga Chlamydomonas reinhardtii and the mature protein of cytochrome oxidase subunit IV. This protein was shown to direct the protein into yeast mitochondria and indicated a low specificity of chloroplast transit peptides. A recent report by Franzén et al. (1990) demonstrates that chloroplast transit peptides from Chlamydomonas reinhard- 
tii share features common with both mitochondrial and higher plant chloroplast presequences. Their potential to form an amphiphilic $\alpha$-helix, which is a general characteristic for mitochondrial presequences, might have resulted in mistargeting (Hurt et al. 1986). A yeast mitochondrial transit peptide can also function in transgenic plants as a dual targeting signal for chloroplasts and mitochondria (Huang et al. 1990). This heterologous system again suggested a low sorting specificity.

In contrast Boutry et al. (1987) and Schmidt and Lonsdale (1989) found no misrouting of a mitochondrial hybrid precursor protein into chloroplasts in a homologous assay system. The sorting was studied in transgenic tobacco plants using a transit peptide for the $\beta$-subunit of the mitochondrial ATPase from tobacco and either chloramphenicol acetyltransferase or $\beta$-glucoronidase as reporter gene product. The specificity of the sorting process is further supported by in vitro studies (Whelan et al. 1990). Again a homologous higher plant system was used. studying routing of the $\beta$-subunit of the mitochondrial ATPase from tobacco and the precursor of the $33 \mathrm{kDa}$ protein of the photosynthetic water splitting complex into isolated plant mitochondria and chloroplasts, respectively. No misrouting was observed and the results suggest a high organellar specificity in plant cells for the recognition and processing (Whelan et al. 1991) of the cytoplasmically synthesized precursor proteins. In conclusion, routing seems to be very specific if a proper experimental system is used; mistargeting is not likely to occur in vivo to any significant extent.

\section{References}

Abad, M.S.. Oblong. J.E. \& Lamppa, G.K. 1991. Soluble chloroplast enzyme cleaves preLHCP made in Escherichia coli to a mature form lacking a basic $\mathrm{N}$-terminal domain Plant Physiol. 96: 1220-1227.

Bartling. D.. Clausmeyer, S.. Oelmüller, R. \& Herrmann. R.G. 1990. Towards epitope models for chloroplast transit sequences. - Bot. Mag. (Tokyo) Special Issue 2: 119-144.

Bassham. D.C. Bartling, D. Mould, R.C., Dunbor , B., Weisbeek. P. Herrmann, R.G. \& Robinson. C. 1991. Transport of proteins into chloroplasts. - J. Biol. Chem. 266: 2360623610.

Boutry, M. Nagy, F., Poulsen, C., Aoyagi, K. \& Chua, N.-H 1987. Targeting of bacterial chloramphenicol acetyltransferase to mitochondria in transgenic plants. - Nature 328: $340-342$.

Buvinger. W.E., Michel, H. \& Bennett, J. 1989. A truncated analog of a pre-light-harvesting chlorophyll $a / b$ protein $I f$ transit peptide inhibits protein import into chloroplast. $-\mathbf{J}$. Biol. Chem. 264: 1195-1202.

Chua, N.-H. \& Schmidt, G.W. 1979. Transport of proteins into mitochondria and chloroplasts. - J. Cell Biol. 81: 461-483.

Cline, K., Werner-Washburne, M., Andrews, J. \& Keegstra, K. 1984. Thermolysin is a suitable protease for probing the surface of intact pea chloroplasts. - Plant Physiol. 75: 675678

Werner-Washburne, M., Lubben, T.H. \& Keegstra, K. 1985. Precursors to two nuclear-encoded chloroplast proteins bind to the outer envelope membrane before being imported into chloroplasts. - J. Biol. Chem. 260: 36913696 .

- Fulsom, D. R. \& Vitanen, P.V. 1989. An imported thyla- koid protein accumulates in the stroma when insertion into thylakoid membranes is inhibited. - J. Biol. Chem. 264: $14225-14232$

- Ettinger. W.F. \& Theg. S.M. 1992. Protein-specific energy requirements for protein transport across the thylakoid membranes. - J. Biol. Chem. 267: 2688-2696.

Comwell, K.L. \& Keegstra. K. 1987. Evidence that a chloroplast surface protein is associated with a specific binding site for the precursor to the small subunit of ribulose-1.5bisphosphate carboxylase. - Plant Physiol. 85: 780-785.

Dahlin. C. \& Cline, K. 1991. Developmental regulation of the plastid protein import apparatus. - Plant Cell 3: 1131-1140.

de Boer, A. D. \& Weisbeek, P.J. 1991. Chloroplast protein topogenesis: import, sorting, and assembly. - Biochim. Biophys. Acta 1071: 221-253.

della-Cioppa, G. \& Kishore, G.M. 1988. Import of a precursor protein into chloroplasts is inhibited by the herhicide glyphosate. - EMBO J. 7: 1299-1305.

Dobberstein. B.. Blobel. G. \& Chua, N.H. 1977. Ifl vitro synthesis and processing of a putative precursor for the small subunit of ribulose-1.5-bisphosphate caboxylase of Chlamydomonas reinhardiii. - Proc. Natl. Acad. Sci. USA 74: 1082-1085.

Dreses-Werringloer, U., Fischer, K., Wachter, E., Link, T.A. \& Flügge, U.-I. 1991. CDNA sequence and deduced amino acid sequence of the precursor of the $37-\mathrm{kDa}$ inner envelope membrane polypeptide from spinach chloroplasts. Its transit peptide contains an amphiphilic $a$-helix as the only detectable structural element. - Eur. J. Biochem. 195: 361368.

Eilers, M. \& Schatz, G. 1986. Binding of a specific ligand inhibits import of a purified precursor protein into mitochondria. - Nature 322: 228-232.

Ellis, R.J. 1990. Molecular chaperones: The plant connection. - Science 250: 954-959.

Flügge. U.1. \& Heldt, H.W, 1981. The phosphate translocator of the chloroplast envelope: Isolation of the carrier protein and reconstitution of transport. - Biochim. Biophys. Acta 638: $296-304$.

- \& Hinz. G. 1986. Energy dependence of protein translocation into chloroplasts. - Eur. J. Biochem. 160: 563-570.

Fischer, K., Gross, A., Sebald, W. Lottspeich, F. \& Eckerskorn, C. I989. The triose phosphate-3-phosphoglycerate-phosphate translocator from spinach chloroplasts: nucleotide sequence of a full-length cDNA clone and import of the in vitro synthesized precursor protein into chloroplasts. - EMBO J. 8: 39-46.

- Weber, A., Fischer, K., Lottspeich, F., Eckerskorn. C. Waegemann, K. \& Soll, J. 1991. The major chloroplast envelope polypeptide is the phosphate translocator and not the protein import receptor. - Nature 353: 364-367.

Franzén, L.-G., Rochaix, J.-D. \& von Heijne, G. 1990 . Chloroplast transit peptides from the green alga Chlamydomonas reinhardiii share features with both mitochondrial and higher plant chloroplast presequences. - FEBS Lett. 260: 165-168.

Friedman, A.L. \& Keegstra, K. 1989. Chloroplast protein import. Quantitative analysis of precursor binding. - Plant Physiol. 89: 993-999.

Grossmann, A., Bartlett, S. \& Chua, N.H. 1980. Energy de pendent uptake of cytoplasmically synthesized polypeptides by chloroplasts. - Nature $285: 525-628$.

Halpin, C., Musgrove, J.E., Lord, J.M. \& Robinson, C. 1989 Import and processing of proteins by castor bean leucoplasts. - FEBS Lett. 258: 32-34.

Hart, F.-U., Pfanner, N.. Nicholson, D.W. \& Neupert, W. 1989. Mitochondrial protein import. - Biochim. Biophys. Acta 988: 1-45.

Hinz, G. \& Flügge, U.I. 1988. Phosphorylation of a $51-\mathrm{kDa}$ envelope membrane polypeptide involved in protein translocation into chloroplasts. - Eur. J. Biochem. 175: 649-659. Huang, J., Hack, E., Thornburg, R.W. \& Myers, A.M. 1990. 
A yeast mitochondrial leader peptide functions in vivo as a dual targeting signal for both chloroplasts and mitochondria. - Plant Cell 2: 1249-1260.

Hurt, E. C., Soltanifar, N., Goldschmidt-Clermont, M., Rochaix, J.-D. \& Schatz, G. 1986. The cleavable pre-sequence of an imported chloroplast protein directs attached potypeptides into yeast mitochondria. - EMBO J. 5: 13431350.

Joyard, J., Billecocq, A., Bartlett, S.G., Block. M.A., Chua, N.-H. \& Douce. R. 1983. Localization of polypeptides to the cytosolic side of the outer envelope membrane of spinach chloroplasts. - J. Biol Chem. 258: 10000-10006

, Block. M.A.\& Douce, R. 1991. Molecular aspects of plastid envelope biochemistry. - Eur. J. Biochem. 199: 489-509.

Kaderbhai, M.A. Pickering, T., Austen, B.M. \& Kadesbhai, N. 1988 . A photoactivatable synthetic transit peptide labels $30 \mathrm{kDa}$ and $52 \mathrm{kDa}$ polypeptides of the chloroplast inner envelope membrane. - FEBS Lett. 232: 313-316.

Karlin-Neumann. G.A. \& Tobin. E.M. 1986r. Transit peptides of nuclear-encoded chloroplast proteins share a common amino acid framework. - EMBO J. 5:9-13.

Keegstra, K. Olsen, L.J. \& Theg, S.M. 1989. Chloroplastic precursors and their transport across the envelope membranes. - Annu. Rev. Plant Physiol. Plant Mol. Biol. 40: $471-501$.

Kerber. B. \& Soll, J. 1992. Transfer of a chloroplast-bound precursor protein into the translocation apparatus is impaired after phospholipase C treatment. - FEBS Lett. 3016: $71-74$

Kiebler. M., Pfaller. R. Sölner, T. Griffiths, G. Horstmann. H., Pfanner. N. \& Neupert, W. 1990. Identification of a mitochondrial receptor complex required for recognition and membrane insertion of precursot proteins. - Nature 348: 610-616.

Kirwin. P.M., Elderfjeld, P.D. \& Robinson. G. 1987. Transport of proteins into chloroplasts. Partial purification of a thylakoidal processing peptidase involved in plastocyanin bogenesis. - J. Biol. Chem. 262: 16386-16390

Klösgen. R.B., Brock. 1.W., Herrmann, R.G.\& Robinson. C. 1992. Proton gradient-driven import of the $16 \mathrm{kDa}$ oxygenevolving complex protein as the full precursor protein by isolated thylakoids. - Plant Mol. Biol. 18: 1031-1034.

Kuntz, M. . Simons, A., Schell, J. \& Schreier, P.H. 1986 Targeting of protein to chloroplasts in transgenic tobacco by fusion to mutated transit peptide. - Mol. Gen. Genet. 205: $454-460$.

Landry. S.J. \& Gierasch. L.M. 1991. Recognition of nascent polypeptides for targeting and folding. - Trends Biochem. Sci. 16: 159-163.

Li. H.-M.. Moore. T. \& Keegstra. K. 1991. Targeting of proteins to the outer envelope membrane uses a different pathway than transport into chloroplasts, - Plant Cell 3 : $709-717$.

Lubben, T.H., Theg, S.M. \& Keegstra, K. 1988. Transport of proteins into chloroplasts. - Photosynth. Res. 17: 173-194.

- Donaldson, G.K. Vitanen. P.V. \& Gatenby. A.A. 1989. Several proteins imported into chloroplasts form stable complexes with the GroEl-related chloroplast molecular chaperone. - Plant Cell 1: 1223-1230.

Marshall, J.S., DeRocher, A.E., Keegstra, K. \& Vierling. E. 1990. Identification of heat shock protein hsp70 homologues in chloroplasts. - Proc. Natl. Acad. Sci. USA 87: 374-378.

Mishkind, M.L. \& Scioli, S.E. 1988. Recent developments in chloroplast protein transport. - Photosynth. Res. 19: 153 184.

Mould, R.M. \& Robinson, C. 1991. A proton gradient is required for the transport of two lumenal oxygen-evolving proteins across the thylakoid membrane. $-\mathbf{J}$. Biol. Chem. 266: 12189-12193.

Neupert, W., Hartl, F.-U., Craig, E.A. \& Pfanner, N. 1990.
How do polypeptides cross the mitochondrial membranes? - Cell 63: $447-450$.

Olsen, L. J. \& Keegstra, K. 1992. The binding of precursor proteins to chloroplasts requires nucleoside triphosphates in the intermembrane space. - J. Biol. Chem. 267: 433-439. - Theg, S. M. Selman. B. R. \& Keegstra. K. 1989. ATP is sequired for the binding of precursor proteins to chloroplasts. - J. Biol. Chem. 264: 6724-6729.

Pain. D. \& Blobel, G. 1987. Protein import into chloroplasts requires a chloroplast ATPase. - Proc. Natl. Acad. Sci. USA 84: $3288-3292$.

- Kanwar, Y.S. \& Blobel, G. 1988. Identification of a receptor for protein import into chloroplasts and its localization to envelope contact zones. - Nature 331: 232-237.

Pelham. H.R.B. 1986. Speculations on the function of the major heat shock and glucose regulated proteins. - Cell 46 : 959-961.

Perry, S.E., Buvinger, W.E., Bennett, J. \& Keegstra. K. 1991. Synthetic analogues of a transit peptide inhibit binding or translocation of chloroplastic precursor proteins. - J. Biol. Chem. 266: 11882-11889

Pilon, M., de Boer, D.A., Knols, S.L., Koppelman. M.H.G.M. van der Graaf, R.M., de Kruijff, B. \& Weisbeek. P.J. 1990. Expression in Escherichia coli and purificrtion of a translocation-competent precursor of the chloroplast protein ferredoxin. - J. Biol. Chem. 265: 3358 3361 .

Salomon, M.. Fischer, K., Flügge. U.-I. \& Soll, J. 1990. Sequence analysis and protein import studtes of an outer chloroplast envelope polypeptide. - Proc. Natl. Acad. Sci. USA 87: $5778-5782$

Schindler, C. \& Soll, J. 1986. Protein transport in intact, purified pea etioplasts. - Arch. Biochem. Biophys. 247: 211220.

- Hracky, R. \& Soll, J. 1987. Protein transport in chloroplasts: ATP is a prerequisite. $-\mathrm{Z}$. Naturforsch. $42 \mathrm{c}: 103-$ 108.

Schmidt. G.W. \& Mishkind. M.L. 1986. The transport of proteins into chloroplasts. - Annu. Rev. Biochem. 55: 879912.

Schnell. D.J.. Blobel, G. \& Pain. D. 1990. The chloroplast import receptor is an integral membrane protein of chloroplast envelope contact sites. - J. Cell Biol. 111: 18251838 .

Blobel. G. \& Pain. D. 1991. Signal peptide analogs derived from two chloroplast precursors interact with the signal recognition system of the chloroplast envelope. $-\mathbf{J}$. Biol. Chem. 266: 3335-3342.

Smeekens. S. \& Weisbeek. P. 1988. Protein transport towards the thylakoid lumen: posttranslational translocation in tandem. - Photosynth. Res. 16: 177-186.

- Bauerle. C.. Hageman. J.. Keegstra. K. \& Weisbeek. P. 1986. The role of the transit peptide in the routing of precursors toward different chloroplast compartments. Cell 46: 365-375.

- Weisbeek. P. \& Robinson. C. 1990. Protein transport into and within chloroplasts. - Trends Biochem. Sci. 15: 73-76.

Smith, S.M. \& Ellis, R.J. 1979. Processing of small subunit precursor of ribulose bisphosphate carboxylase and $j$ ts assembly into whole enzyme are stromal events. - Nature 278: $662-664$.

Soll, J. \& Waegemann, K. 1992. A functionally active protein import complex from chloroplasts. - Plant J. 2: 253-256.

Strzalka, K. Ngernprasirtsiri, J.. Watanabe, A. \& Akazawa, I. 1987. Sycamore amyloplasts can import and process precursors of nuclear encoded chloroplast proteins. - Biochem. Biophys. Res. Commun. 149: 799-806.

Theg, S.M., Bauerle, C., Oisen, L.J., Selman, B.R. \& Keegstra, K. 1989. Internal ATP is the only energy requirement for the translocation of precursor proteins across chloroplastic membranes. - J. Biol. Chem. 264: 6730-6736

von Heijne, G. \& Nishikawa, K. 1991. Hypothesis: Chlo- 
roplast transit peptides. The perfect random coil? - FEBS Lett. 278: 1-3.

- Steppuhn. J. \& Herrmann. R.G. 1989. Domain structure of mitochondrial and chloroplast targeting peptides. - Eur. J. Biochem. 180: $535-545$.

Waegemann. K. \& Soll. J. 1991. Characterization of the prorein import apparatus in isolated outer envelopes of chloroplasts. - Plant J. 1: 149-158.

- Paulsen. H.\& Soll, J. 1990. Translocation of proteins into isolated chloroplasts requires cytosolic factors to obtain import competence. - FEBS Lett. 261: 89-92.

- . Eichacker, S. \& Sol]. J. 1992. Outer envelope membranes from chloroplasts are isolated as right-side-out vesicles. Planta 187: 89-94

Wasmann. C.C. Reis. B.. Bartlett. S.G. \& Bohnert, H.J.
1986. The importance of the transit peptide and the transported protein for protein import into chloroplasts. - Mol. Gen. Genet. 205: 446-453.

Whelan, J. Knorpp, C. \& Glater, E. 1990 . Sorting of precursor proteins betwees isolated spinach leaf matobondria and chloroplasts. - Plant Mol. Biol. 14: 977-982.

- Knorpp. C. Harmey. M.A. \& Glaser. E. 1991. Specificity of leaf mitochondrial and chloroplast processing systems for nuclear-encoded precursor proteins. - Plant Mol. Biol. 16: $283-292$.

Willey. D.L., Fischer, K. Wachter. E., Link. T. A. \& Flüggc U,-]. J991. Moleculat cloning and structural analysis of the phosphate translocator from pea chloroplasts and its comparison to the spinach phosphate translocator. - Planta 18.3 : $451-461$. 